\title{
On Models of Racial Prejudice and Urban Residential Structure ${ }^{\mathrm{I}}$
}

\author{
Paul N. Courant \\ Department of Economics and Institute of Public Policy Studies, \\ University of Michigan, Ann Arbor, Michigan 48104 \\ AND \\ JOHN YINGER \\ Department of City and Regional Planning, Harvard University, \\ Cambridge, Massachusetts 02138
}

Received July 7, 1975

\begin{abstract}
Economists have studied the effects of racial prejudice on urban residential structure using a set of models that focus on conditions at the border between the black and white areas. This paper is a review of the theoretical literature on these border models and an investigation of their generality. The main result derived in the paper is that border models are logically inconsistent without unrealistic assumptions either about the incomes of blacks relative to the incomcs of whites or about the extent of white prejudice. The paper concludes with several suggestions for more satisfactory modeling of prejudice and urban structure.
\end{abstract}

\section{INTRODUCTION}

Understanding the effects of racial prejudice on urban residential structure is important for at least two reasons. First, prejudice is a powerful and pervasive attitude that affects the residential locations of many families. Second, it is important for policy purposes to separate the effects of prejudice per se, which does not necessarily imply discrimination, from the effects of discriminatory behavior. ${ }^{2}$ In particular, it is necessary to determine how much,

${ }^{1}$ This paper is the result of several years work, both independent and collective, by the two authors. Much of that work took place under the wise and stimulating guidance of Edwin S. Mills. We gratefully acknowledge his many contributions to this paper. We are also grateful for helpful comments received at various times from James Ohls and Alan Deardorff. Support was provided to John Yinger by the Institute for Research on Poverty at the University of Wisconsin.

${ }^{2}$ For one statement showing that prejudice does not imply discrimination, see [4]. For a more complete discussion, see [20]. 
if any, of residential segregation and racial differentials in housing prices can be explained by attitudes rather than by discrimination.

A major analytical tool used by economists to study these issues is a set of "border models." 3 These models apply to completely segregated cities (with blacks in the city center) in which price and locational adjustments are made with reference to conditions at the border between the black and white areas. The purpose of this paper is to review and extend the theoretical literature on border models: in particular, to determine the generality of these models and to suggest alternative approaches to studying situations for which the models are inapplicable.

\section{BAILEY'S BORDER MODEL}

The original border model was presented by Bailey [2] and has been extended by Muth $[15,16]$. The Bailey model is based on the assumption that the population of a city is divided into two groups, $X$ and $Y$; that Group $X$ prefers to live near Group $Y$; and that Group $Y$ prefers to live away from Group $X$. Since it is clear that Bailey intends Groups $X$ to represent blacks and Group $Y$ to represent whites, ${ }^{4}$ our subsequent discussion will refer to blacks and whites. Bailey also assumes that blacks and whites are completely segregated with blacks living on blocks A, B, C, and D, and whites living on blocks E, F, G. . . . Residents of border blocks, D and E, are considered to be near the other group; everyone else is considered to be far from the other group, that is, in an interior area. These assumptions lead to the conclusion that unit housing prices are higher at $\mathrm{D}$ than in the black interior, and lower at $\mathbf{E}$ than in the white interior. Furthermore, if there is perfect competition, equilibrium requires that housing prices at the border be the same for both groups.

Figure 1 illustrates these conclusions. ${ }^{5}$ The Bailey model operates under perfect (but segregated) competition, so the price of a single house is given by $\mathrm{BB}^{\prime}$ in the black area and by $\mathrm{WW}^{\prime}$ in the white area. If each housing firm owned a single house, every firm on block $E$ would have an incentive to sell to blacks rather than to whites, since doing so would increase its revenue by $\left(B^{\prime}-W\right)$. Thus, the border would move to the right. As it moved, the

\footnotetext{
${ }^{3}$ See, for example, Bailey $[2,3]$, Courant $[5,6]$, Rose-Ackerman [19], King and Mieszkowski [12], Muth $[15,16]$, and Daniels [8].

${ }^{4} \mathrm{~A}$ note on these assumptions about tastes is in order. Surveys reveal that most whites prefer not to live with blacks and that a majority of blacks prefer to live in integrated neighborhoods (see [17]). These results do not imply, however, that whites are prejudiced and that blacks have "reverse" prejudice, since the surveys cannot separate purely racial attitudes from attitudes about the public service levels in neighborhoods with different racial compositions.

${ }^{5}$ The diagram can be found in $[5,21,16]$. Note that $\mathbf{B B}^{\prime}$ and $\mathbf{W W}^{\prime}$ are price curves determined by the intersection of demand curves and vertical supply curves.
} 


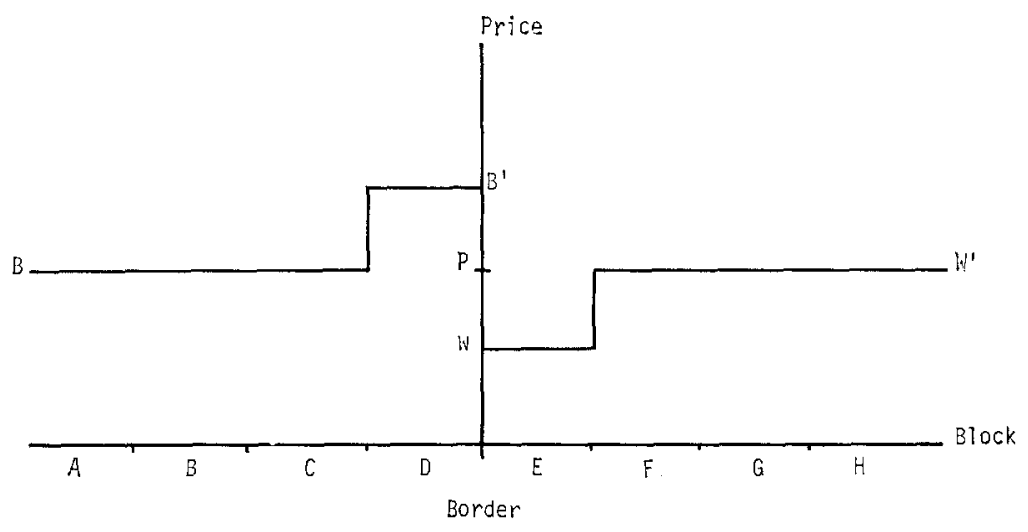

FIGURE 1

supply of houses in the black area would increase and $\mathbf{B B}^{\prime}$ would shift downward. An equilibrium would be reached when the price in the black border area $\left(\mathrm{B}^{\prime}\right)$ equaled the price in the white border area (W). At such an equilibrium, the price in the white interior is higher than the price in the black interior. ${ }^{6}$

One feature of the Bailey model not recognized in the literature is that the model does not have an equilibrium without the assumption that city size is fixed. If city size were not fixed, housing firms would attempt to capture the economic rent associated with housing in the white interior by building new all-white housing at the outer edge of the city. Thus, competition would drive down the price of housing in the white interior. If, as the Bailey logic indicates, the black-white border responded to such a downward shift in the white price curve, then the city would continue to grow and the black-white border would continue to move outward, until the city reached physical barriers to further expansion - that is, until it reached a fixed size.

The existence of nonresidential land use, such as agriculture, does not lead to an equilibrium in the Bailey model in a city that can grow. If competition

'Bailey also considers the case of a "redeveloper" who owns blocks D, E, and F. In this case, Bailey concludes that starting from the situation in our Fig. 1, a shift of the border one block to the right would increase the firm's revenue on block $E$ but would decrease its combined revenue on blocks $D$ and $F$ by the same amount. Thus, in the case of a large firm, equilibrium occurs when the two interior prices are equal. There are, however, two problems with Bailey's analysis. First, unlike a one-block move, a two-block move to the right would increase the firm's revenue. (We are grateful to Robert Dennis for pointing this out.) Second, a large firm may be aware of the shifting of the $\mathbf{B B}^{\prime}$ and $\mathbf{W W}^{\prime}$ curves that accompanies movement of the border. For example, if as the border moves to the left the $\mathrm{BB}^{\prime}$ curve shifts upward much faster than the $W^{\prime} W^{\prime}$ curve shifts downward, then a redeveloper might maximize its profits by moving the border to the left of its position in Fig. 1. For a more detailed discussion of this case, see [21]. 
lowered the price of land in the white interior to the nonresidential rental rate, and if a Bailey "equilibrium" were obtained with border prices equal, then nonresidential users would be willing to pay more for land than owners of housing in the black interior or at the black-white border. Thus, nonresidential activities would move into the center of the city, the black price curve would shift upward, and the black-white border would move to the right.

\section{GENERAL EQUILIBRIUM BORDER MODELS}

Both Courant $[5,6]$ and Rose-Ackerman [19] have extended Bailey's border model concept by introducing racial prejudice into a general equilibrium model of urban residential structure as developed by Alonso [1], Mills [13, 14], and Muth [15].7 These extensions lead not only to an equilibrium in a border model (by tying a city together with commuting cost) but also to several precise statements about the effects of prejudice on urban structure.

The Courant and Rose-Ackerman models of prejudice and urban structure assume, like Bailey's model, that blacks and whites are completely segregated with blacks in the city center. ${ }^{8}$ They also assume, following Bailey, that white utility is affected by distance from blacks. On the other hand, they assume that blacks have no preferences with regard to the race of their neighbors.

${ }^{7}$ Urban models of this type assume, largely for mathematical convenience, that location has only one dimension: distance from the CBD. Although this assumption is very unreaslistic, it is not our intention to critize the urban models on which general equilibrium border models are based; instead, we analyze these border models on their own ground and determine their applicability within the framework of a one-dimensional urban model. When multidimensional urban models become available, perhaps the analysis of the relationship between prejudice and urban structure can be given a more satisfactory foundation.

${ }^{8}$ It is well known that there is extensive racial residential segregation in cities and that the black population is highly centralized. One natural way to include these facts in an urban model is to assume that blacks inhabit a central annulus. Rose-Ackerman $[19$, p. 90] justifies this assumption by arguing that blacks have lower average incomes than whites and that in urban models higher-income groups locate farther from the city center than lower-income groups. Courant proves that if incomes are equal or if all blacks have lower incomes than any white, the only equilibrium pattern of location in a border model is one in which blacks inhabit the central annulus of the city instead of the outer annulus [5, p.68; 6, p. 16]. (In Section III of this paper we show that the assumption that blacks inhabit only the central annulus is not, in general, consistent with a situation in which some blacks have significantly higher incomes than some whites. The average incomes of the races are irrelevant to the question.) Finally, it can be argued that the equilibrium shape for the black area is the shape that minimizes contact between blacks and whites along the black-white border. If the black area is of any other shape in a one-income-class model, there will cxist a series of Pareto-optimal moves. Yinger [23] shows that in a city that is less than about $10 \%$ black, this equilibrium shape is a central circle. 
The white utility function is

$$
U_{\mathrm{w}}=U_{\mathrm{w}}(Z, H, D),
$$

where $Z$ is a composite consumption good, $H$ is housing services, and $D$ is "social distance" from blacks. All the partial derivatives of this function are assumed to be positive. Social distance is an increasing function of physical distance, or $D=D^{*}\left(u-u^{*}\right)=D(u)$, where $u$ is the distance from the CBD at which the white family lives and $u^{*}$ is the location of the black-white border. Since white utility increases with distance from the border, $D^{\prime}(u)$ is positive at $u^{*}$. In addition, $D^{\prime \prime}(u)$ is negative and $D^{\prime}(u)$ reaches zero at some large value of $\left(u-u^{*}\right)$; whites who are already far from blacks do not increase their utility by moving a little farther away.

Finally, whites face the budget constraint

$$
Y=P_{z} Z+P_{\mathrm{w}}(u) H+T(Y, u),
$$

where $Y$ is income, $P_{z}$ is the price of $Z, P_{\mathrm{w}}(u)$ is the price paid by whites per unit of $H$ at location $u$, and $T$ is round-trip commuting cost to the CBD. The maximization of (1) subject to (2) results in the following locational equilibrium condition for whites: ${ }^{9}$

$$
P^{\prime}{ }_{\mathrm{w}}(u)=-T_{u} / H+\left[\partial U_{\mathrm{w}} / \partial D(u)\right] D^{\prime}(u) / \lambda H .
$$

This cquation can be interpreted as a market cquilibrium condition; it defines the $P_{\mathrm{w}}(u)$ function that makes whites indifferent to their location. Equation (3) reveals that $P^{\prime}{ }_{\mathrm{w}}(u)$ is ambiguous in sign and, as illustrated in Fig. 2, may be increasing near the black-white border, where $D^{\prime}(u)$ is large.

Using a specific utility function, one can solve this type of model explicitly for the price-distance function, $P_{\mathrm{w}}(u)$. For example, suppose that per-mile commuting costs $(t)$ are constant and that whites have the Cobb-Douglas utility function

$$
U_{\text {w }}=a_{1} \log Z+a_{n} \log H+a_{3} \log D .
$$

Whites maximize (4) subject to (2)-with $t$ substituted for $T(Y, u)$. Using the first-order conditions to eliminate $H$ and $\lambda$ from (3) and defining $k=a_{2} /\left(a_{1}+a_{2}\right)$ yields

$$
P_{\mathrm{w}}^{\prime}(u) / P_{\mathrm{w}}(u)=-t / k(Y-t u)+a_{3} D^{\prime}(u) / a_{2} D(u) .
$$

Integrating (5) leads to

$$
P_{\mathrm{w}}(u)=K(Y-t u)^{1 / k} D(u)^{a_{3} / a_{2}},
$$

${ }^{9}$ Equation (3) is the first-order condition with respect to $u$ of the white household's maximization problem, where $\lambda$ is the Lagrangian multiplier. Although the notation is different, our Eq. (3) is the same as Rose-Ackerman's Eq. (7), except that she neglected to include $\lambda$. 


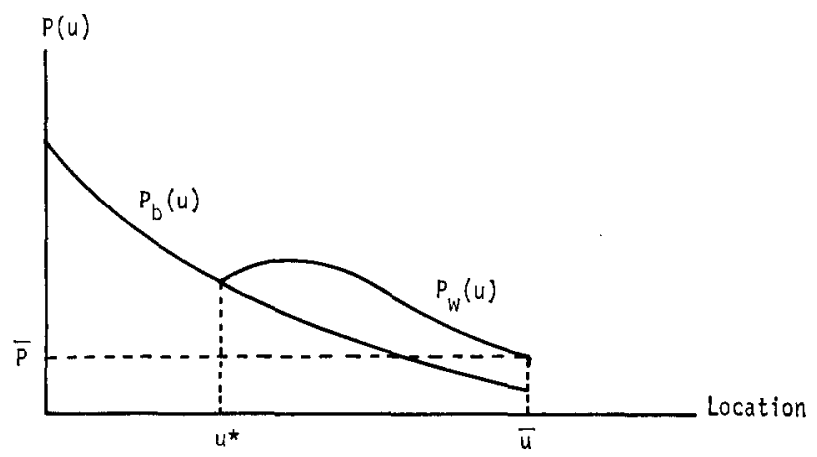

Figure 2

where $K$ is a constant of integration. Anchoring this price-distance function at the outer edge of the city $(\bar{u})$ using the equation, ${ }^{10} P_{\mathrm{w}}(\bar{u})=\bar{P}$, we obtain

$$
P_{\mathrm{w}}(u)=\bar{P}[(Y-t u) /(Y-t \bar{u})]^{1 / k}[D(u) / D(\bar{u})]^{a_{3} / a_{2}} .
$$

The terms in (6) that reflect white prejudice can be interpreted as the proportion by which the unit price of housing, as determined by commuting costs, must be lower at $u$ to compensate whites for nearness to blacks. It will prove useful to define the inverse of these terms, evaluated at $u=u^{*}$, as

$$
\bar{D}=\left[D(\bar{u}) / D\left(u^{*}\right)\right]^{a_{3} / a 2} .
$$

$\bar{D}$ is an indicator of the strength of white prejudice. It gives the proportional increase in the unit price of housing that whites would be willing to pay (if there were no transportation costs) to live $\left(\bar{u}-u^{*}\right)$ miles away from blacks instead of right next to blacks.

Five main results about urban structure can be derived from this type of model:11

1. The white price-distance function is flatter when whites have racial prejudice than when they do not and may be upward-sloping near the blackwhite border (see $[5$, p. $56 ; 19$, p. 91]). Courant points out that in these models, higher housing prices imply higher land prices and thus higher capital-land ratios in housing production. This result has the testable implication that there is capital substitution - that is, a belt of relatively high-rise buildings-near the black-white border $[5$, p. 70$]$.

2. Blacks pay less for housing and live at lower densities when whites are prejudiced than when whites are not prejudiced $[5$, p. $61 ; 19$, p. 92$]$.

${ }^{10}$ Given the production function for housing, a unique $\bar{P}$ will be implied by $\bar{R}$, the rental rate for agricultural land. See [14, Chap. 5] for a complete discussion of the model.

${ }^{11}$ Note that these results do not depend on the functional form used in the above exposition. 
3. Most whites, but not those near the black-white border, pay more for housing and live at higher densities than they would in a city without white prejudice $[19$, p. 92]. This result is consistent with nonspatial competitive models in which whites "pay for their prejudice."

4. Under certain values of the parameters of the white price-distance function, there exists a zone of nonresidential land use between the black and the white residential areas. In this "graybelt," which occurs when whites offer less for housing at $u^{*}$ than at $\bar{u}$, land used for housing has a marginal value product less than the nonresidential rental rate so that no housing is produced [5, p. 56].

5. A city of given population has more area if it contains prejudiced whites than if it does not $[6$, p. $11 ; 19$, p. 92].

\section{BORDER MODELS WITH MORE THAN ONE INCOME CLASS}

Border models depend on the assumption of a single income class. In this section we show that when more than one income class exists in a city, both Bailey's and the general equilibrium border models apply only to a very restricted set of cities.

To understand why the single-income-class assumption is important, it is helpful to emphasize one characteristic of the Bailey model: Blacks are assumed to prefer living near whites but to end up living away from whites. But if blacks prefer to live near whites, why do they not move into white neighborhoods? Muth $[15,16]$ answers this question by assuming that all whites are willing to pay more to live in a white neighborhood than are any blacks. Muth does not offer evidence to support this assumption, but it does make the Bailey model consistent; that is, it describes a situation in which blacks prefer integration but do not achieve it.

Muth's assumption is not plausible, however, if there is a range in black incomes. The amount a family is willing to pay to live in a white area is a function of its income as well as of its attitudes; for any given amount that a white is willing to pay to live in a white area, there is some income that will lead a black to be willing to pay even more. So if there is a range in black incomes, the Bailey model is consistent only if yet another assumption is made: The income of the richest black must be sufficiently low relative to the income of the poorest white that the richest black will not outbid the poorest white for housing in a white neighborhood.

In our view, this second assumption is so strong that it leaves the Bailey model with little practical interest. Table 1 presents some evidence to support our view: It indicates that in a variety of cities, about one-quarter of the black families have incomes above the mean income for white families.

The Courant and Rose-Ackerman models lead to equilibrium in a Baileylike world and enrich our understanding of the effect of prejudice on urban 


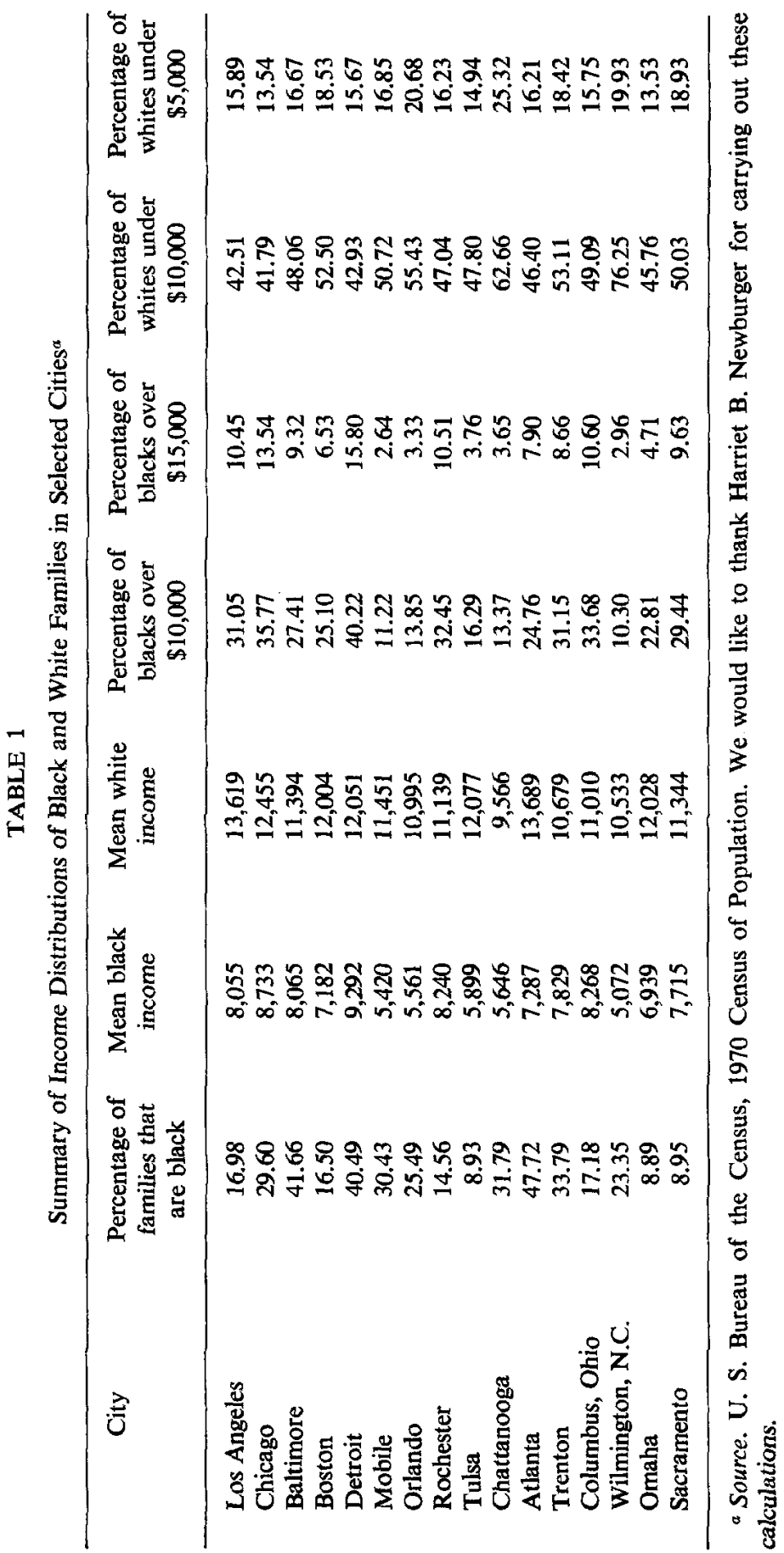


structure. We show, however, that these models are also unsatisfactory when there is more than one income class. By way of review, general equilibrium border models combine several assumptions about perfect competition in the housing market with several Bailey-like assumptions about white prejudice. Of particular interest for what follows is the assumption that blacks and whites each live in one and only one region of a city so that there is a single black-white border.

Four properties of the price-distance functions in these models are important for our discussion.

1. Whenever the income elasticity of demand for housing is unity or greater, both the black and the white price-distance functions become flatter as income rises (see $[14,15]$ ). This result can be derived in the Cobb-Douglas case by differentiating Eq. (5) with respect to income.

2. Unless there is a graybelt, the black and white price-distance functions meet at $u^{*}$; that is $P_{\mathrm{w}}\left(u^{*}\right)=P_{\mathrm{b}}\left(u^{*}\right)$. This property is a product of competition; if the black and white prices are not equal at $u^{*}$, either blacks or whites will be willing to pay more than the other group on either side of the border, and the border will move.

3. Where $D^{\prime}(u)$ is positivc, the whitc price-distance function is flatter than it would otherwise be and may be upward sloping near $u^{*}$.

4. At distances far from the black-white border, where $D^{\prime}(u)$ is assumed to be zero, white prejudice has no effect on the slope of the price-distance function. This property follows from Eq. (3).

These four properties are sufficient to prove that if some black incomes are higher than white incomes, the black and white price-distance functions will cross at some $\hat{u}$ greater than $u^{*}$. It follows from properties 2 and 3 that just outside $u^{*}$ the white price-distance function is above the black pricedistance function. ${ }^{12}$ Furthermore, it follows from properties 1 and 4 that at locations far from $u^{*}$ the black price-distance function will be flatter than the white price-distance function whenever black incomes are higher than white incomes. Therefore, the white price-distance function will eventually fall to a point at which the black price-distance function intersects it from the left. The higher black incomes are relative to white incomes, the lower will be the value of $\hat{u}$ at which the two price-distance functions cross.

If, as illustrated in Fig. 3, the point of intersection between the two pricedistance functions occurs within the urban arca (that is, if $\hat{u}$ is less than $\bar{u}$ ), then blacks will be willing to pay more for housing than will whites both inside $u^{*}$ and outside $\hat{u}$. Under these conditions, rich blacks will "hop"

12 If there is a graybelt, the black price at the inner edge of the graybelt equals the white price at the outer edge of the graybelt (equals $\bar{P}$ ). In such a case, therefore, this sentence should conclude: "just outside the graybelt the white price-distance function is above the black price-distance function." This restatement does not affect the following argument. 


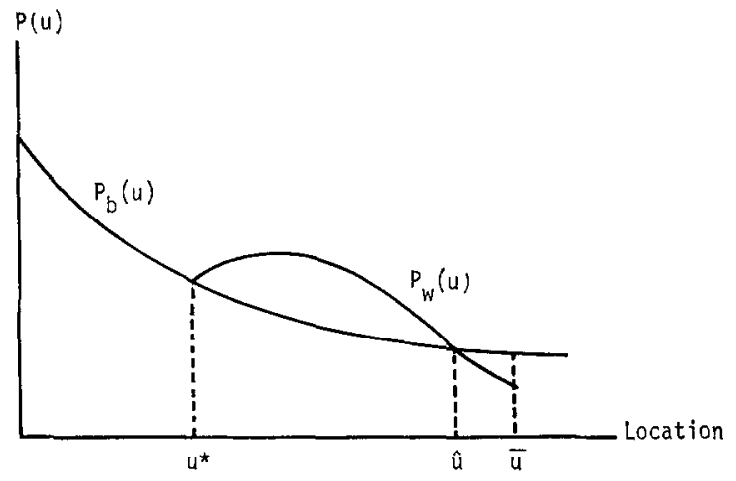

Figure 3

over poorer whites and the equilibrium solution to the model will involve two black areas - thereby contradicting one of the assumptions of the model. In this case, in other words, border models are logically inconsistent. This inconsistency is important because the models' assumptions about white prejudice depend on the existence of a single black-white border. The models provide no way to determine the effect of white prejudice on the equilibrium price-distance function if blacks live in two areas-so that there are three black-white borders.

If the black price-distance function intersects the white price-distance function outside the urban area (that is, if $\hat{u}$ is greater than $\tilde{u}$ ), then general equilibrium border models are logically consistent; in equilibrium, there will be only one black area and one white area, and blacks will live in the city center. It does not follow, however, that there will literally be a black-white border. If prejudice has a strong effect on the white price-distance function, then whites may bid more for housing at $\bar{u}$ than at $u^{*}$. In this case, which is illustrated in Fig. 4, nonresidential users of land will outbid both whites and

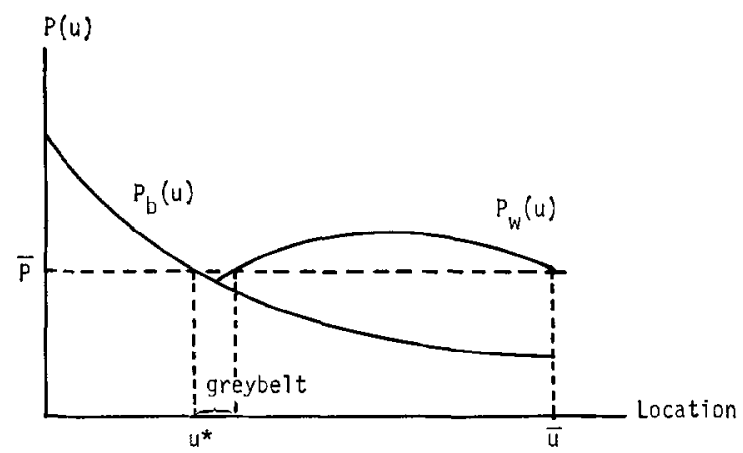

FIGURE 4 
blacks for land near $u^{*}$ and, in equilibrium, there will be a graybelt of nonresidential land use between the black and white areas.

Only if $P_{\mathrm{w}}(\bar{u})$ is less than $P_{\mathrm{w}}\left(u^{*}\right)$ and $\hat{u}$ occurs beyond $\bar{u}$ is there a logically consistent border model that actually involves a black-white border. As we will see, this case is possible even if black incomes are infinite, but it appears to involve very high levels of white prejudice. This case is illustrated by Fig. 2.

These results are summarized in the following theorem, which is already proved.

THEOREM. Given the assumptions of general equilibrium border models, and assuming that some blacks have higher incomes than some whites, equilibrium in the location of blacks vis a vis lower-incomes whites requires that one of the following cases occur:

1. Blacks are willing to pay a higher unit price than are whites for housing beyond some $\hat{u}$ (where $u^{*}<\hat{u}<\bar{u}$ ), so that, in equilibrium, there is more than one black area. In this case, the pattern of racial segregation assumed by border models is not an equilibrium and the models are logically inconsistent.

2. White prejudice is so strong that whites are willing to pay a higher unit price for housing at $\bar{u}$ than at $u^{*}$. In this case, the pattern of segregation assumed by the models is an equilibrium and a zone of nonresidential land use separates the black and whites areas.

3. The black and white price-distance function do not intersect between $u^{*}$ and $\bar{u}$ and the white price-distance function is lower at $\bar{u}$ than at $u^{*}$, so that the pattern of segregation assumed by border models is an equilibrium and there exists a black-white border. This case most closely coincides with the spirit of the Bailey model.

The reasoning behind this theorem is complicated somewhat by the introduction of several white income classes, but the above statement of the theorem is still valid. Since price-distance functions are steeper at lower incomes, the introduction of white low-income classes near $u^{*}$ makes larger the range of parameters under which blacks hop. Similarly, the introduction of white high-income classes in the suburbs lessens the downward slope of the white price-distance function and makes smaller the range of parameters under which hopping occurs.

It is also possible to extend the model to include the attitudes of blacks. If, as surveys indicate, many blacks prefer to live in integrated neighborhoods, then blacks may offer more to live in white neighborhoods than assumed above. If so, the black price-distance function will be flatter and the likelihood of hopping will be greater.

Although the logic behind our theorem is perfectly rigorous, it is appropriate to state the results in more mathematical terms. The following mathematical derivation of the theorem assumes a Cobb-Douglas utility function 
and linear commuting costs, but the theorem does not depend on these somewhat restrictive assumptions.

As shown earlier, the equilibrium condition for whites is

$$
P_{\mathrm{w}}(u)=\bar{P}\left[\left(Y_{\mathrm{w}}-t_{\mathrm{w}} u\right) /\left(Y_{\mathrm{w}}-t_{\mathrm{w}} \bar{u}\right)\right]^{1 / k}\left[D(u) /(D(\bar{u})]^{a_{3} / a_{2}} .\right.
$$

The analogous condition for blacks is ${ }^{13}$

$$
P_{\mathrm{b}}(u)=P_{\mathrm{w}}\left(u^{*}\right)\left[\left(Y_{\mathrm{b}}-t_{\mathrm{b}} u\right) /\left(Y_{\mathrm{b}}-t_{\mathrm{b}} u^{*}\right)\right]^{1 / k} .
$$

The incentive of blacks to hop over whites depends on the condition ${ }^{14}$

$$
P_{\mathrm{b}}(\bar{u})>P_{\mathrm{w}}(\bar{u})=\bar{P} .
$$

If inequality (10) holds, then blacks will bid more than whites for housing at $\bar{u}$ and therefore will not be in equilibrium in the city center. Now from (8) and (9) we find that

$$
P_{\mathrm{b}}(\bar{u})=\bar{P}\left(\frac{D\left(u^{*}\right)}{D(\bar{u})}\right)^{a_{3} / a_{2}}\left(\frac{Y_{\mathrm{w}}-t_{\mathrm{w}} u^{*}}{Y_{\mathrm{w}}-t_{\mathrm{w}} \bar{u}}\right)^{1 / k}\left(\frac{Y_{\mathrm{b}}-t_{\mathrm{b}} \bar{u}}{Y_{\mathrm{b}}-t_{\mathrm{b}} u^{*}}\right)^{1 / k} .
$$

Thus, inequality (10) will hold if

$$
\left(\frac{D\left(u^{*}\right)}{D(\bar{u})}\right)^{a_{3} / a_{2}}\left(\frac{Y_{\mathrm{w}}-t_{\mathrm{w}} u^{*}}{Y_{\mathrm{w}}-t_{\mathrm{w}} \bar{u}}\right)^{1 / k}\left(\frac{Y_{\mathrm{b}}-t_{\mathrm{b}} \bar{u}}{Y_{\mathrm{b}}-t_{\mathrm{b}} u^{*}}\right)^{1 / k}>1 .
$$

Linear commuting costs for group $i$ can be expressed in the form $t_{i}=t_{0}+t_{y} Y_{i}$, where $t_{0}$ is the per-mile operating cost and $t_{y}$ is the per-mile time cost of a round trip to the CBD. Substituting this expression into (11), we have

where

$$
\left(\frac{1}{\bar{D} W}\right)\left(\frac{Y_{\mathrm{b}}\left(1-t_{y} \bar{u}\right)-t_{0} \bar{u}}{Y_{\mathrm{b}}\left(1-t_{y} u^{*}\right)-t_{0} u^{*}}\right)^{1 / k}>1,
$$

$$
W=\left(\frac{Y_{\mathrm{w}}\left(1-t_{y} \bar{u}\right)-t_{0} \bar{u}}{Y_{\mathrm{w}}\left(1-t_{y} u^{*}\right)-t_{0} u^{*}}\right)^{1 / k}
$$

${ }^{13}$ There are two differences between the white and black functions: (1) Since blacks are assumed to be indifferent to the race of their neighbors, social distance does not affect Eq. (9). (2) The black price-distance function is anchored to the white price-distance function at $u^{*}$; hence, $P_{\mathrm{w}}\left(u^{*}\right)$ in Eq. (9) is analogous to $\bar{P}$ in Eq. (8). If there is a graybelt, $u^{*}$ is the outer edge of the black area and the black price-distance function is anchored by the equation, $P_{b}\left(u^{*}\right)=\bar{P}$. Finally, note that subscripts to denote black and white have been added to the right-hand sides of Eqs. (8) and (9).

14 In general, if there are many white income classes, and borders between white income classes are denoted $\tilde{u}$, we need only determine if $P_{\mathrm{b}}(\tilde{u})>P_{\mathrm{w}}(\tilde{u})$, for any $\tilde{u}$. The logic of the argument is most easily followed, however, if the discussion takes place in terms of $\bar{u}$. In doing this, we are not arguing that in order for the theorem to hold the richest blacks must outbid the richest whites. 
and $\bar{D}$ is defined by (7).

In analyzing inequality (12), it is useful to begin by determining the highest level of white prejudice at which hopping by blacks can occur. Since as $Y_{\mathrm{b}}$ approaches infinity, the ratio of $\left[Y_{\mathrm{b}}\left(1-t_{y} \bar{u}\right)-t_{0} \bar{u}\right]$ to $\left[Y_{\mathrm{b}}\left(1-t_{y} u^{*}\right)-t_{0} u^{*}\right]$ approaches $\left(1-t_{y} \bar{u}\right) /\left(1-t_{y} u^{*}\right)$, it follows from (12) that hopping is logically possible as long as

$$
(1 / \bar{D} W)\left[\left(1-t_{y} \bar{u}\right) /\left(1-t_{y} u^{*}\right)\right]^{1 / k}>1 .
$$

The level of $\bar{D}$ at which inequality (13) holds as an equality can be called the no-hop point $\left(=D_{\mathrm{h}}\right)$; this point is the level of white prejudice above which blacks, no matter how high their incomes, will not have an incentive to hop over whites. In symbols,

$$
D_{\mathrm{h}}=(1 / W)\left[\left(1-t_{y} \bar{u}\right) /\left(1-t_{y} u^{*}\right)\right]^{1 / k} .
$$

As indicated earlier, graybelts form if

$$
P_{\mathrm{w}}\left(u^{*}\right)<P_{\mathrm{w}}(\bar{u})=\bar{P}
$$

or

$$
\bar{P}\left[\left(Y_{\mathrm{w}}-t_{\mathrm{w}} u^{*}\right) /\left(Y_{\mathrm{w}}-t_{\mathrm{w}} \bar{u}\right)\right]^{1 / k}\left[D\left(u^{*}\right) / D(\bar{u})\right]^{a_{3} / u_{2}}<\bar{P}
$$

or

$$
1 / \bar{D} W<1 \text {. }
$$

The level of $\bar{D}$ above which graybelts will form will be referred to as the graybelt point and labeled $D_{\mathrm{g}} \cdot{ }^{15}$ Thus

$$
D_{\mathrm{g}}=1 / W .
$$

Finally, we can determine the minimum level of income at which blacks will have an incentive to hop over whites by making inequality (12) into an equality and solving for $Y_{\mathrm{b}}$ :

$$
Y_{\mathrm{b}}=\frac{t_{0}\left[\bar{u}-(W \bar{D})^{k} u^{*}\right]}{1-t_{y} \bar{u}-(W \bar{D})^{k}\left(1-t_{i} u^{*}\right)} .
$$

These results can be extended in several ways. First, if there are three white income classes referred to by the superscripts $H, M$, and $L$, the price-distance functions for all three classes must meet at the boundaries between classes. Thus, $P_{\mathrm{b}}\left(u^{*}\right)=P_{\mathrm{w}}^{\mathrm{L}_{\mathrm{w}}}\left(u^{*}\right), P_{\mathrm{w}}^{\mathrm{L}_{\mathrm{w}}}\left(u_{1}\right)=P^{\mathrm{M}}{ }_{\mathrm{w}}\left(u_{1}\right), P^{\mathrm{M}_{\mathrm{w}}}\left(u_{2}\right)=P^{\mathrm{H}_{\mathrm{w}}}\left(u_{2}\right)$, and $P^{\mathrm{H}}{ }_{\mathrm{w}}(\bar{u})=\bar{P}$, where $u_{1}$ and $u_{2}$ refer to borders between income classes. From these conditions (and the assumption that white prejudice does not vary by

${ }^{15}$ By differentiating $D_{h}$ with respect to the parameters of the model it can be shown that the higher white incomes, the larger the black area, the greater the proportion of income spent on housing, the smaller the city, and the smaller the costs of commuting, the less white prejudice is required to eliminate the possibility of black hopping. Similarly, the lower white incomes, the smaller $u^{*}$ and $k$, and the greater $\bar{u}, t_{0}$, and $t_{y}$, the less white prejudice is required to lead to graybelts. 
income class), we find that $P_{\mathrm{b}}(\bar{u})$ will exceed $\bar{P}$ if ${ }^{16}$

where

$$
\left(1 / \bar{D} W^{*}\right)\left[\left(1-t_{y} \bar{u}\right)\left(1-t_{y} u^{*}\right)\right]^{1 / k}>1,
$$

$$
\begin{aligned}
& W^{*}=W^{\mathrm{H}} W^{\mathrm{M}} W^{\mathrm{L}} \\
& W^{\mathrm{H}}=\left[\left(Y_{\mathrm{w}}^{\mathrm{H}}\left(1-t_{y} \bar{u}\right)-t_{0} \bar{u}\right) /\left(Y_{\mathrm{w}}^{\mathrm{H}}\left(1-t_{y} u_{2}\right)-t_{0} u_{2}\right)\right]^{1 / k} \\
& W^{\mathrm{M}}=\left[\left(Y_{\mathrm{w}}^{\mathrm{M}_{\mathrm{w}}}\left(1-t_{y} u_{2}\right)-t_{0} u_{2}\right) /\left(Y_{\mathrm{w}}^{\mathrm{M}}\left(1-t_{y} u_{1}\right)-t_{0} u_{1}\right)\right]^{1 / k} \\
& W^{\mathrm{L}}=\left[\left(Y_{\mathrm{w}}^{\mathrm{L}_{\mathrm{w}}}\left(1-t_{y} u_{1}\right)-t_{0} u_{1}\right) /\left(Y^{\mathrm{L}_{\mathrm{w}}}\left(1-t_{y} u^{*}\right)-t_{0} u^{*}\right)\right]^{1 / k}
\end{aligned}
$$

Inequality (17) is identical to (13) except that $W$ has been replaced by $W^{*}$. It follows that formulas (14) and (15) are valid in the three-income-class case if $W^{*}$ is substituted for $W$. These formulas can be extended to any number of white income classes or to the case in which white prejudice varies with income class.

Second, black attitudes can be introduced in a manner analogous to that of white prejudice. In this case the black price-distance function becomes

$$
P_{\mathrm{b}}(u)=P_{\mathrm{w}}\left(u^{*}\right)\left[\left(Y_{\mathrm{b}}-t_{\mathrm{b}} u\right) /\left(Y_{\mathrm{b}}-t_{\mathrm{b}} u^{*}\right)\right]^{1 / k}\left[D_{\mathrm{b}}(u) / D_{\mathrm{b}}\left(u^{*}\right)\right]^{a_{3} / a_{2}}
$$

where $D_{\mathrm{b}}$ is the social-distance function perceived by blacks. Substituting (18) for (9), the no-hop point becomes

where

$$
D_{\mathrm{h}}=\left[\bar{D}_{\mathrm{b}} / W\right]\left[\left(1-t_{y} \bar{u}\right) /\left(1-t_{y} u^{*}\right)\right]^{1 / a},
$$

$$
\bar{D}_{\mathrm{b}}=\left[D_{\mathrm{b}}(\bar{u}) / D_{\mathrm{b}}\left(u^{*}\right)\right]^{\mathrm{as}_{3} / a_{2}} \text {. }
$$

A black preference for integration implies that $\bar{D}_{\mathrm{b}}$ is greater than unity and increases the level of white prejudice required to eliminate the possibility of hopping by blacks. ${ }^{17}$

The results of this section can be illustrated by some numerical examples. Let us assume that operating costs are 15 cents per mile, that commuting proceeds at $12 \mathrm{mph}$ and travel time is valued at one-half the wage rate, that whites earn $\$ 10,000$ per year, and that people spend one-fifth of their income on housing. Translated into daily terms, these assumptions imply that $t_{0}=0.3 ; t_{y}=0.0104 ; Y_{\mathrm{w}}=40$; and $k=0.2$. Now let us examine two cities with the dimensions shown in Table 2 ; if there is hopping or a graybelt, these assumed values for $\bar{u}$ and $u^{*}$ are not equilibrium values. ${ }^{18}$

\footnotetext{
${ }^{16}$ Note again that it is still possible for blacks to hop over some, but not all, whites. As before, one can compute the condition for hopping to an arbitrary $\tilde{u}$, a location where a white income class poorer than blacks and one richer than blacks have a border.

${ }^{17}$ If the black preference for integration is stronger than white prejudice, blacks will have an incentive to move into the white area even in a single-income-class model. However, the assumptions in border models about white prejudice do not allow for the possibility of whites and blacks living at the same location, so that the equilibrium pattern of location (if any) cannot be determined in this special case.

${ }^{18}$ In an urban model of this type, either population or the dimensions of the city must be
} 
TABLE 2

Dimensions, No-Hop Points, and Graybelt Points for Cities A and B

\begin{tabular}{|c|c|c|}
\hline & \multicolumn{2}{|c|}{ City } \\
\hline & A & B \\
\hline $\bar{u}$ & 15 & 10 \\
\hline$u^{*}$ & 2 & 3 \\
\hline$D_{\mathrm{h}}$ & 1.8928 & 1.3766 \\
\hline$D_{\mathrm{g}}$ & 3.9788 & 2.0344 \\
\hline
\end{tabular}

The values of $D_{\mathrm{h}}$ and $D_{\mathrm{g}}$ can be calculated using (14) and (15). The results, which are presented in Table 2, indicate that for the possibility of black hopping to be eliminated in city $\mathrm{A}$, whites must be willing to pay $89 \%$ more for their housing in order to avoid blacks. The analogous figure for city B is $38 \%$. Table 2 also indicates that there will be a consistent border model with a black-white border in city A (B) only if whites are willing to pay between 89 and $298 \%$ ( 38 and $103 \%$ ) more for housing in order to live as far from blacks as possible.

It is possible to calculate, using (16), how high the incomes of the richest blacks would have to be at various levels of $\bar{D}$ in order for those blacks to have an incentive to hop over whites. Such calculations for cities A and B are presented in Table 3. This table shows that at low levels of white prejudice rich blacks will have an incentive to hop if their incomes are only slightly greater than white incomes. As white prejudice approaches $D_{\mathrm{h}}$, rich blacks will not have an incentive to hop unless their incomes are many times those of whites.

These examples can be extended in several ways. First, additional white income classes can be added. Take, for illustration, two cities, $\mathrm{A}^{*}$ and $\mathrm{B}^{*}$, with white income classes earning $\$ 5000, \$ 10,000$, and $\$ 20,000$, and with the dimensions shown in Table 4. In light of the data in Table 1, these distributions of white income appear fairly realistic. Calculations of $D_{\mathrm{h}}$ and $D_{\mathrm{g}}$ for cities $A^{*}$ and $B^{*}$ are given in Table 4 . The addition of white higher-income classes to this example decreases the range of parameters for which blacks have an incentive to hop, and the addition of white lower-income classes increases this range. The overall effect is to slightly increase $D_{\mathrm{h}}$ and $D_{\mathrm{g}}$.

Finally, the effect of black attitudes can be calculated using (19). Table 5 presents the calculations of $D_{\mathrm{h}}$ for cities $\mathrm{A}^{*}$ and $\mathrm{B}^{*}$ at various levels of black preference for integration. For example, Table 5 indicates that if

exogenous. Here we are assuming that population is given and that $\bar{u}$ and $u^{*}$ adjust so that there is room for the given population. It is also possible to assume that $\bar{u}$ and $u^{*}$ are fixed and let net migration occur until population just fills up the area of the city. 
TABLE 3

Levels of Black Income above Which Black Hopping Will Occur, for Various Levels of White Prejudice

\begin{tabular}{|c|c|c|c|c|}
\hline \multirow[t]{3}{*}{$\bar{D}$} & \multicolumn{4}{|c|}{ City } \\
\hline & \multicolumn{2}{|c|}{ A } & \multicolumn{2}{|c|}{ B } \\
\hline & Daily $Y_{b}$ & Yearly $Y_{\mathrm{b}}$ & Daily $Y_{b}$ & Yearly $Y_{k}$ \\
\hline 1 & $\$ 40.00$ & $\$ 10,000$ & $\$ 40.00$ & $\$ 10,000$ \\
\hline 1.05 & 43.06 & 10,765 & 46.82 & 11,705 \\
\hline 1.10 & 46.49 & 11,623 & 56.08 & 14,020 \\
\hline 1.20 & 54.78 & 13,623 & 90.26 & 22,565 \\
\hline 1.30 & 65.80 & 16,450 & 213.49 & 53,376 \\
\hline 1.3766 & 77.09 & 19,273 & $\infty$ & $\infty$ \\
\hline 1.40 & 81.22 & 20,305 & - & - \\
\hline 1.50 & 104.42 & 26,105 & - & - \\
\hline 1.60 & 143.36 & 35,840 & - & - \\
\hline 1.70 & 222.55 & 55,638 & - & - \\
\hline 1.80 & 472.03 & 118.008 & - & - \\
\hline 1.8928 & $\infty$ & $\infty$ & - & $\ldots$ \\
\hline
\end{tabular}

blacks are willing to pay $5 \%$ more for housing in white than in black neighborhoods, the no-hop point in city B* goes from 43 to $50 \%$. Black preferences do not change the graybelt point.

These calculations can be compared to an empirical estimate of $\bar{D}$. The only convincing such estimate of which we are aware is provided by King and Mieszkowski [12], who found that white rentals for equivalents apartments were $7 \%$ lower in the black-white boundary zone than in the white interior. This result implies that the value of $\bar{D}$ is $(1 /(1-0.07))=1.075$. Thus, in all of our calculations the level of prejudice necessary to achieve

TABLE 4

Dimensions, No-Hop Points, and Graybelt Points for Cities $\mathrm{A}^{*}$ and $\mathrm{B}^{*}$

\begin{tabular}{|c|c|c|}
\hline & \multicolumn{2}{|c|}{ City } \\
\hline & $A^{*}$ & $\mathbf{B}^{*}$ \\
\hline$u^{*}$ & 2 & 3 \\
\hline$u_{1}$ & 6 & 5 \\
\hline$u_{2}$ & 11 & 8 \\
\hline$\vec{u}$ & 15 & 10 \\
\hline$D_{\mathrm{b}}$ & 2.0105 & 1.4309 \\
\hline$D_{B}$ & 4.2262 & 2.1147 \\
\hline
\end{tabular}


TABLE 5

No-Hop Points in Cities $A^{*}$ and $B^{*}$, for Various Levels of Black Preference for Integration

\begin{tabular}{ccc}
\hline $\begin{array}{c}\text { Level of } \\
\text { black preference } \\
\text { for integration }\end{array}$ & \multicolumn{2}{c}{ City } \\
\cline { 2 - 3 } & $\mathrm{A}^{*}$ & $\mathrm{~B}^{*}$ \\
\hline 1.05 & 2.1110 & 1.5025 \\
1.10 & 2.2116 & 1.5740 \\
\hline
\end{tabular}

the no-hop point, and thus, to render the border model internally consistent, is much larger than that found by King and Mieszkowski and larger than is easy to believe.

\section{IMPLICATIONS OF THE ANALYSIS}

The preceding discussion casts serious doubt on the appropriateness of both general equilibrium models and simple Bailey models as frameworks for the study of the effects of racial prejudice on urban structure. When realistic assumptions about income distribution are added to the models, the Bailey model breaks down, and the general equilibrium models are logically inconsistent unless levels of white prejudice are extremely high. In the Cobb-Douglas case, the level of white prejudice necessary for consistency in the general equilibrium models is, with our weakest set of assumptions, over five times as high as the level in the best empirical study of how much whites are willing to pay to live far from blacks [12]. We therefore conclude that since many blacks have much higher incomes than many whites, one of the most attractive features of the border models-their assumption of one ghetto in a world where one ghetto is the rule-is consistent with the models themselves. Having concluded this, we suggest that the following areas of research hold promise for better modeling of the questions border models were designed to address.

1. It may be possible, although it looks very difficult, to create competitive models of urban structure in which black-white borders are endogenous. Rather than assuming a pattern of residential location for blacks, such models must be able to solve for the equilibrium configuration of spatial sorting by race and income, given an assumption about the distribution of income. However, designing such models is complicated, and we know of nothing in the literature that tells us how to begin. Furthermore, our results strongly suggest that equilibrium solutions to competitive monocentric models of urban structure involve spatial allocations of residences such that blacks of different incomes are separated by whites of different incomes; while the development of a model capable of solving for endogenous borders 
might "save" the border model concept, it will not generate single ghettos, which are what we observe.

2. Another line of inquiry involves the construction of models of cities in which the ghetto is not circular. Suppose, for example, that the ghetto is wedge-shaped, thereby giving high-income blacks access to distant locations without hopping over whites. Again, we know little about how to build such models, except that preliminary attempts on our part to model the relationships at the borders of a wedge strongly suggest that the set of conditions under which competitive equilibria at these borders exist is very small, if not empty.

3. Another possibility is that the effects of prejudice on a competitive housing market can be modeled in ways other than those implicit in the border models. In particular, Courant [7] has shown that if there are positive costs of search for housing, and if some whites are adverse to selling to blacks, blacks rationally may choose not to search for housing in white parts of town even if they are willing to pay more than the going price of housing in those parts of town. Thus, there may be a barrier to black hopping due to search costs. However, this will not, in general, be an impermeable barrier, and Courant also suggests that it will be most permeable for higher-income blacks.

4. Finally, competitive models may not be the appropriate vehicle for analysis of these issues. One of the clear implications of our analysis is that both poor and rich whites are made worse off by black hopping. Consequently, it is very much in the interest of prejudiced whites, as a group, to organize housing markets in a manner that prevents high-income blacks from hopping. Thus, the competitive models presented here have within them a strong suggestion that housing markets in fact are not competitive-that there are strong incentives for the larger, richer, and more powerful elements of society to collude. A similar conclusion has been reached by Yinger [24] using a different specification of racial prejudice in an urban model. Yinger shows that if whites prefer not to live with blacks and if some blacks prefer to live in integrated neighborhoods, then competition cannot generate a stable equilibrium distribution of blacks and whites in an urban area. In this situation it is in the interest of whites to buy neighborhood stability by restricting the areas into which blacks can move.

It is interesting to note that if whites are able to discriminate against blacks in the housing market, border models may provide useful insights about the effects of white prejudice in white locations. In this paper we have argued that border models cannot determine the equilibrium pattern of residential location for blacks and whites. However, if the pattern of location is determined by discrimination against blacks, then the border model approach can determine the equilibrium pattern of housing prices for whites. 
To be specific, if high- and low-income blacks live in the city center because they are excluded from the rest of the city, then the equilibrium white pricedistance function is given by Eq. (3).

A variety of studies suggest that discrimination against blacks is an important feature of urban housing markets. Kain, in a number of works with a number of collaborators ${ }^{19}$ has argued that whites organize housing markets to artifically restrict the range of locations available to blacks. Yinger [22] and Courant [5] document a number of ways in which two important institutions in these markets, real estate brokers and bankers, find it in their interest to promote racial segregation through their market behavior. For the case of realtors, Helper [9] finds a great deal of evidence to support the contention that collusive, discriminatory behavior takes place.

Economists have tended to ignore what they perceive to be the essentially sociological question of whether or not a society in which racial prejudice is pervasive might organize itself so that the shared attitude is reflected in its institutions. And the sociological literature strongly suggests that prejudice does pervade institutional and individual behavior. ${ }^{20}$ To ignore these findings in studying the effect of racial prejudice on urban structure is to leave unturned what may be a very large stone.

\section{REFERENCES}

1. W. Alonso, "Location and Land Use," Harvard Univ. Press, Cambridge, Mass. (1964).

2. M. J. Bailey, A note on the economics of residential zoning and urban renewal, Land Econ., 35, 288-292 (1959).

3. M. J. Bailey, Effects of race and other demogragphic factors on the values of singlefamily homes, Land Econ., 42, 215-220 (1966).

4. G. S. Becker, "The Economics of Discrimination," Univ. of Chicago Press, Chicago (1957).

5. P. N. Courant, Economic aspects of racial prejudice in urban housing markets, Ph.D. dissertation, Princeton University, Princeton, N. J. (1973).

6. P. N. Courant, Urban residential structure and racial prejudice, Institute of Public Policy Studies Discussion Paper No. 62, University of Michigan, Ann Arbor (1974).

7. P. N. Courant, Racial prejudice in a search model of the urban housing market, J. Urban Econ., to appear.

8. C. B. Daniels, The influence of racial segregation on housing prices, J. Urban Econ., 2, 105-122 (1975).

9. R. Helper, "Racial Policies and Practices of Real Estate Brokers," Univ. of Minnesota Press, Minneapolis (1969).

10. J. F. Kain, The effect of housing market segregation on urban development, in "Savings and Residential Financing: 1969 Conference Proceedings" (D. P. Jacobs and R. T. Pratt, Eds.), U. S. Savings and Loan League, Chicago (1969).

11. J. F. Kain and J. M. Quigley, "Housing Markets and Racial Discrimination," National Bureau of Economic Research, New York (1975).

${ }^{19}$ See, for example, Kain [10], Kain and Quigley [11], and Quigley [18].

${ }^{20}$ See, for example, [20, Chap. 4] and the references cited therein, 
12. A. T. King and P. Mieszkowski, Racial discrimination, segregation and the price of housing, J. Polit. Econ., 81, 590-606 (1973).

13. E. S. Mills, An aggregative model of resource allocation in a metropolitan area, Amer. Econ. Rev., 58, 197-210 (1967).

14. E. S. Mills, "Urban Economics," Scott, Foresman and Company, Glenview, Ill. (1972).

15. R. F. Muth, "Cities and Housing," Univ. of Chicago Press, Chicago (1969).

16. R. F. Muth, "Urban Economic Problems," Harper and Row, New York (1975).

17. T. F. Pettigrew, Attitudes on race and housing: a social-psychological view, in "Segregation in Residential Areas" (A. H. Hawley and V. P. Rock, Eds,), National Academy of Sciences, Washington, D. C. (1973).

18. J. M. Quigley, Racial discrimination and housing consumption of black households, in "Patterns of Racial Segregation, Vol. I: Housing" (G. M. von Furstenberg, B. Harrison, and A R. Horowitz, Eds.), D. C. Heath, Lexington, Mass. (1974).

19. S. Rose-Ackerman, Racism and urban structure, J. Urban Econ., 2, 85-103 (1975).

20. G. E. Simpson and J. M. Yinger, "Racial and Cultural Minorities: An Analysis of Prejudice and Discrimination," 4th ed., Harper and Row, New York (1972).

2l. J. Yinger, Three essays on the economics of discrimination in housing, Ph.D. dissertation, Princeton University, Princeton, N.J. (1974).

22. J. Yinger, An analysis of discrimination by real estate brokers. Institute for Research on Poverty Discussion Paper No. 252-75, University of Wisconsin, Madison (1975).

23. J. Yinger, A note on the length of the black-white border, J. Urban Econ., 3, 370-382 (1976).

24. J. Yinger, Racial prejudice and racial residential segregation in an urban model, $J$. Urban Econ., 3, 383-396 (1976). 